\title{
Malaria in South Africa: 110 years of learning to control the disease
}

\author{
M Coetzee, ${ }^{1} \mathrm{PhD}$; P Kruger, ${ }^{2} \mathrm{DPh} ; \mathbf{R}$ H Hunt, ${ }^{1} \mathrm{PhD} ; \mathbf{D}$ N Durrheim, ${ }^{3} \mathrm{DrPH}$, FAFPHM; J Urbach,${ }^{4}$ MCom (Economics); C F Hansford, ${ }^{2} \mathrm{MB}$ ChB \\ ${ }^{1}$ Wits Research Institute for Malaria, Faculty of Health Sciences, University of the Witwatersrand, Johannesburg, South Africa \\ ${ }^{2}$ Malaria Control Programme, Polokwane, Limpopo Province, South Africa \\ ${ }^{3}$ School of Public Health Medicine, University of Newcastle, New South Wales, Australia \\ ${ }^{4}$ Africa Fighting Malaria, Durban, South Africa
}

Corresponding author: $M$ Coetzee (maureenc@nicd.ac.za)

\begin{abstract}
In Africa today, the drive towards controlling malaria is comparable with efforts made in the 1950s and 1960s during the World Health Organization's Global Malaria Eradication Campaign. Unlike the Eradication Campaign that 'covered' the globe but excluded Africa, the current endeavours focus on Africa, but not to the exclusion of the rest of the tropical and sub-tropical world. Major donor agencies are partnering with African governments in an attempt to curb transmission of malaria parasites, and in some countries on the edges of the distribution of malaria, there is talk of eliminating the disease. South Africa is at the very southernmost fringe of malaria distribution on the African continent and has a long history of intense malaria control activities. This article looks at what South Africa has achieved in the past and where it needs to go in the future, not only to maintain the status quo, but hopefully to eliminate transmission of the disease within its borders.
\end{abstract}

S Afr Med J 2013;103(10 Suppl 2):770-778. DOI:10.7196/SAMJ.7446

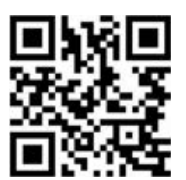

\section{The early days}

The causative agent of malaria was determined in the 1890s by the individual works of Laveran, Grassi and Ross, as a parasite belonging to the genus Plasmodium and transmitted to humans by anopheline mosquitoes. ${ }^{[1]}$ Prior to this, fevers were associated with 'bad air' (in Italian 'mal aria'), swamps and other unsavoury localities.

In South Africa (SA), the first well-documented case of the devastating effects of malaria was probably that of the Louis Trichardt trek to Maputo, Mozambique in 1837 - 1838, when 20 of the 53 members of the party died of malaria, including Trichardt's wife. ${ }^{[2,3]}$ Trichardt himself died of malaria 6 months later. Laidler and Gelfand, ${ }^{[4]}$ in their book on the medical history of SA, make brief reference to malaria being 'a most serious ailment in the Transvaal Republic' and in the 1830s immigrants to Natal 'suffered great losses from malaria and other fever ${ }^{2[5]}$ In those early days, of course, diagnosis was purely clinical and was based on the pattern of high fever with attendant high mortality rates.

After the discovery in the 1890s that malaria was caused by a parasite transmitted by anopheline mosquitoes, the next report on malaria in SA was by Hill and Haydon ${ }^{[6]}$ on the 1904/05 malaria epidemic in Natal. In Durban alone, between the end of January and end of June 1905, 4177 cases of malaria were recorded with 42 deaths (malaria had been declared a compulsory notifiable disease in Durban in 1902). ${ }^{[7]}$ At the beginning of the epidemic, blood smear examination showed mainly benign tertian malaria (Plasmodium vivax), while later, as the epidemic increased, cases of severe tertian malaria ( $P$. falciparum) became prevalent. Quinine tablets were used to treat the malaria cases. Extensive mosquito surveys found a sporozoite infection rate of $9.1 \%$ in Anopheles costalis (An. gambiae s.l.) collected inside houses and dissected within 2 days of capture. Hill and Haydon ${ }^{[6]}$ stated that they were 'unable to advance any sound reason to account for this epidemic', there being no dramatic change in climatic factors compared with previous years when no malaria transmission took place. ${ }^{a}$ Their stated impression was that the larvicidal measures implemented had no apparent impact on the epidemic, and they concluded that 'only the prophylactic use of quinine appears to give promise. Murison, ${ }^{[8]}$ however, in Ronald Ross' book 'The Prevention of Malaria', provided his account of the 1905 epidemic and the subsequent antimalarial activities of 1906 - 1907. He reported that the larviciding and larval source management in the borough of Durban had been very successful compared with the areas outside of the borough where malaria transmission continued unabated. After the 1905 epidemic in Natal, malaria again became rare and no cases were reported from Durban up to 1918.

Also in Ross' book is a section on malaria control in SA along the railway line from Pretoria to Delagoa Bay (Maputo, Mozambique). Bostock $^{[0]}$ states that no attempt was made to combat malaria until he was appointed District Surgeon in Komatipoort in 1903. He goes on to describe the most amazing and intense implementation of antimalarial measures he organised that were funded by the Central South African Railways. Every station, house and cottage from Waterval Onder to Komatipoort was mosquito-proofed, mosquito breeding habitats in the vicinity of the stations were 'dealt with', free quinine was available and intense larval source management carried out in the town of Komatipoort. Malaria case figures presented for 1903 - 1905 show an overall reduction of $87.5 \%{ }^{[9]}$

In 1921, Pratt-Johnson ${ }^{[7]}$ published a paper on the distribution of malaria in SA and a mosquito survey of areas around military hospitals. The military hospitals visited by Pratt-Johnson and inspected for mosquito breeding were situated in Cape Town, Durban, Potchefstroom and Pretoria (Roberts Heights, now known as Thaba Tshwane). Two specimens of An. costalis were collected from Roberts Heights as larvae, almost certainly being Anopheles

\footnotetext{
"It is possible that this epidemic may have been exacerbated by An. funestus, an African vector species that had only just been described the year before. This species, whose preferred larval habitats are swamps and slow-moving streams, would not have been affected by the larviciding of temporary pools that are the preferred breeding sites of the An. gambiae complex mosquitoes.
} were abundant. 
quadriannulatus. This species was described and named in 1911 by $\mathrm{F}$ Theobald from material collected north of Pretoria and it is one of the cattle-feeding, non-vector, members of the An. gambiae complex in SA.

Flooding along the Orange River in 1909 caused a severe epidemic in the districts of Gordonia, Kenhardt and Upington (bordering on Botswana and Namibia), stretching into Namaqualand and the Kalahari, and further east into what is today the North West Province. No information was available on the mosquito populations involved in this epidemic.

A small outbreak of malaria occurred in February 1918 in a localised area in Durban, presumed to have been initiated by a group of Indians returning from East Africa and infecting locally breeding 'An. costalis'. These cases were diagnosed on blood smears as benign tertian (P. vivax) malaria. ${ }^{[7]}$

In the Transvaal, vivax and falciparum malaria were equally prevalent in the period under review, with $P$. vivax tending to occur more frequently at higher altitudes on what is known as the Middleveld, while P. falciparum was common in Lowveld areas. ${ }^{\text {b }}$

\section{From the Roaring Twenties to the end of World War II}

The Department of Medical Entomology was established by the South African Institute for Medical Research (SAIMR) in 1925 under the headship of Alexander Ingram. ${ }^{[5]}$ He was joined in 1926 by Botha de Meillon (Fig. 1) (later to become head of the department from 1931 to 1960) and together

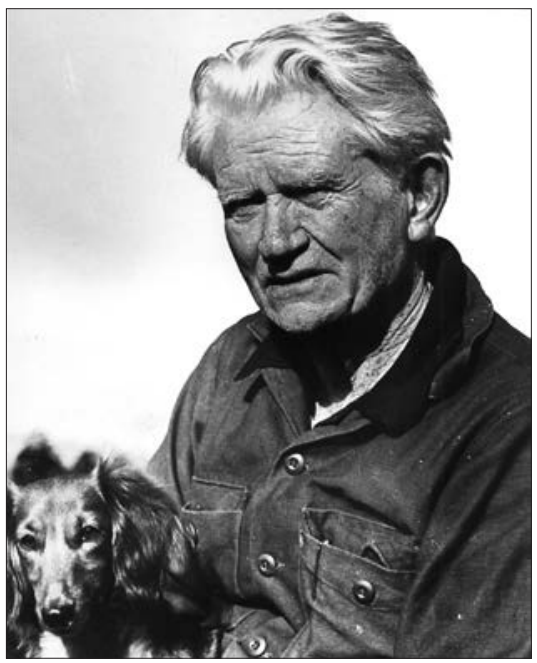

Fig. 1. Botha de Meillon (1902 - 2000), aged 80.

There is a possibility that the 'vivax' malaria could have been Plasmodium ovale, which was only recognised as a separate malaria species in the 1920s. Nevertheless, it is interesting to introduction of indoor residual spraying in the 1950s. they undertook the first extensive mosquito surveys of SA covering the Transvaal and Zululand. ${ }^{[10]}$ Ingram and De Meillon ${ }^{[1]}$ confirmed the insecticidal properties of pyrethrum, while De Meillon ${ }^{[12,13]}$ demonstrated the powerful influence that indoor spraying with pyrethrum would have on malaria transmission (see below), this being the forerunner of the World Health Organization's (WHO's) global malaria eradication campaign over 20 years later.

In 1930, two prominent malariologists visited SA. The first was Sir Malcolm Watson, a distinguished British scientist from the London School of Hygiene and Tropical Medicine, who spent most of his time fighting malaria in Malaysia. He visited SA on his way north to mining communities in Northern Rhodesia (Zambia) in July 1930. ${ }^{[14]}$ His major contribution to malaria control in SA was to persuade the government that malaria had economic significance, not just medical importance ${ }^{[5]}$ Malaria continued to devastate some of the richest agricultural areas in SA for another 15 years.

Professor N H Swellengrebel, another world-renowned malariologist, from the University of Amsterdam, visited SA in the latter half of 1930 and was accompanied by De Meillon and Siegfried Annecke on a tour of the Lowveld areas to investigate the malaria situation. The comprehensive report that resulted from this visit ${ }^{[15]}$ recommended the implementation of 'species sanitation', this being the specific targeting of malaria vector mosquitoes with control interventions, excluding those mosquito species not involved in malaria transmission. This required insight into the behaviour of the malaria vectors and subsequently led directly to indoor spraying with pyrethrum. ${ }^{[13,16]}$

Swellengrebel also recommended the establishment of a malaria station in Tzaneen. The SAIMR, at the request of the government,

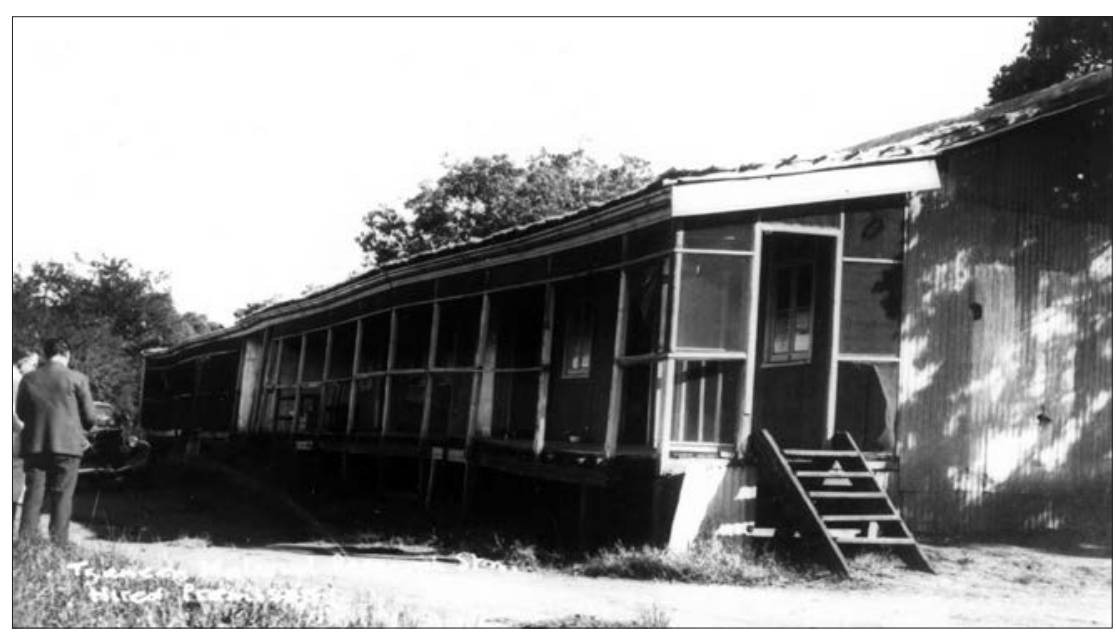

Fig. 2. The malaria station in Tzaneen, 1932. erected this station (Fig. 2) in 1932 under the Annecke for control. ${ }^{[17,18]}$ Another station was established in Eshowe, Natal, in 1934. These stations were to provide the basic facilities for De Meillon to demonstrate the utility of indoor spraying with pyrethrum as a highly effective measure against adult, indoor resting anopheline mosquitoes. ${ }^{[1,13]}$

\subsection{Natal}

Severe malaria epidemics occurred in Natal from 1929 to 1933. During this time, railway construction and sugar production came to a standstill and almost one million quinine tablets were distributed by the health authorities. During the 1931 malaria transmission season, cases were reported from as far south as Port St Johns and in 1932 there were 22132 deaths from malaria. ${ }^{[5,19]}$ The 1933 Annual Report of the Union Government Department of Public Health refers to 15 malaria committees in the Natal coastal areas and voluntary farm groups in the midlands who supervised the mosquito control measures. Training courses were held for malaria inspectors and mosquito 'spotters'. Similar measures were implemented in the rural areas where the chiefs, officials, missionaries and storekeepers were involved. By 1941/42, 35800 huts were being sprayed weekly with pyrethrum, protecting over 100000 people.

A Pan-African Health Conference was held in Johannesburg in 1936 under the auspices of the Health Organization of the League of Nations. Two papers were delivered describing the 1930 - 1933 major malaria epidemics in Natal and Zululand and the effects of insecticides for bringing it under control. ${ }^{[13,16]}$

Park Ross ${ }^{[16]}$ described in great detail the malaria control activities in place from 1930 leadership of De Meillon for research ${ }^{[5]}$ and 
Table 1. Results of house spraying with a pyrethrum/kerosene mixture in Natal in $1935^{[13]}$

\begin{tabular}{lllll}
\hline & $\begin{array}{l}\text { Spleen rate } \\
\text { (\% reduction } \\
\text { over 6 months) }\end{array}$ & $\begin{array}{l}\text { Total mosquitoes } \\
\text { collected over 6 } \\
\text { months } \boldsymbol{N}\end{array}$ & $\begin{array}{l}\text { An.gambiae } \\
\text { infected } \\
\boldsymbol{n}\end{array}$ & $\begin{array}{l}\text { Infection } \\
\text { rate } \\
\%\end{array}$ \\
\hline Section I - daily & 90.7 & 70 & 2 & 2.86 \\
Section II - bi-weekly & 63.6 & 130 & 2 & 1.54 \\
Section III - weekly & 50 & 76 & 6 & 7.89 \\
Section IV - control & 21.1 & Not done & 8 & -
\end{tabular}

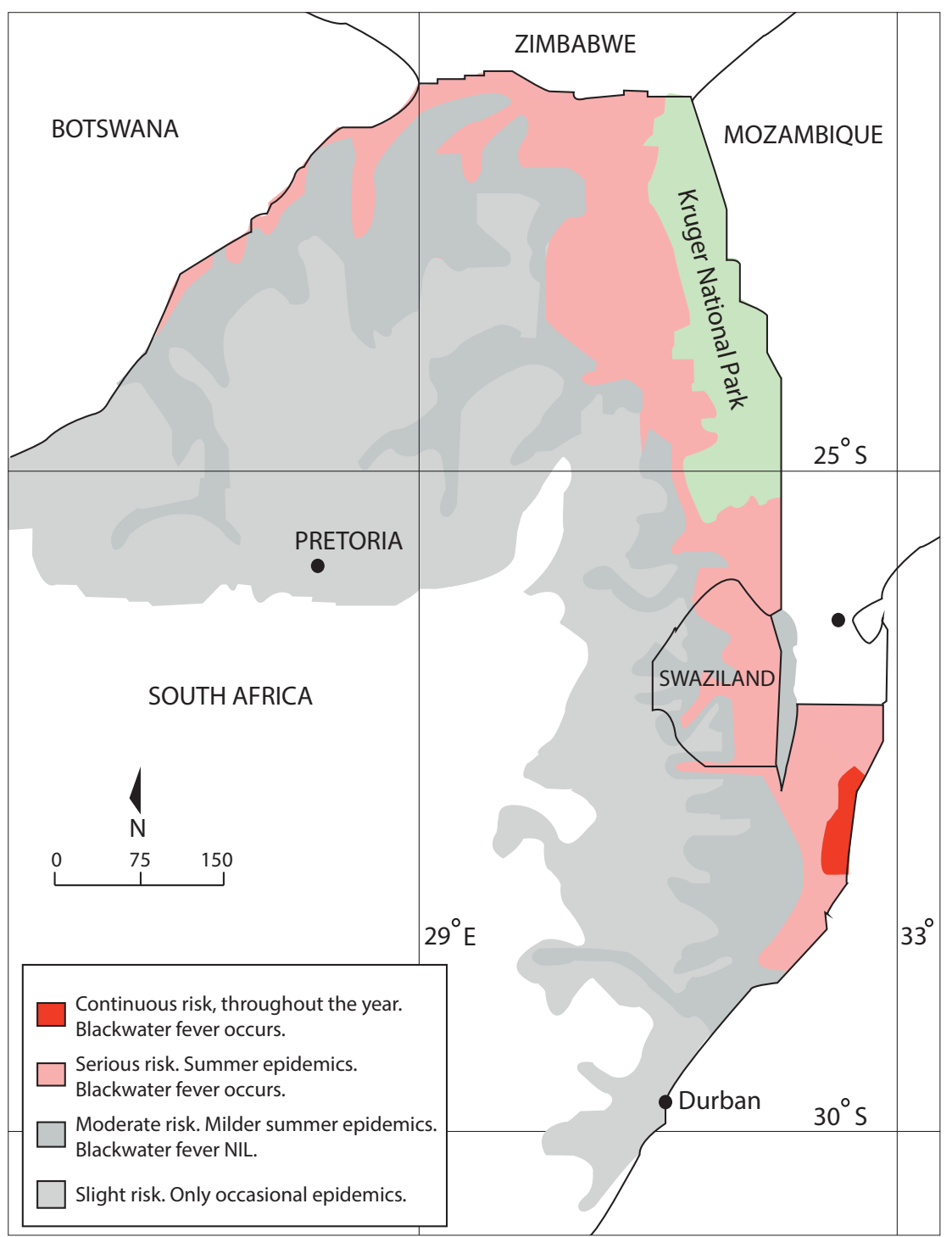

Fig. 3. Malaria in South Africa, 1938.

onwards. While he was cautious in drawing conclusions from the available data, it nevertheless appeared that administration of quinine and the use of anti-larval measures were unsuccessful. Park Ross referred to larviciding as 'wasting time' and the distribution of quinine among a population not trained to use the drug as unreliable. On the other hand, the use of insecticide sprays had resulted in a dramatic drop in to May 1935. A rural area was divided into 4 sections: ( $i$ ) each hut sprayed daily with pyrethrum in kerosene; (ii) each hut sprayed bi-weekly; (iii) each hut sprayed once a week; and (iv) unsprayed control huts. The results are summarised in Table 1.

It is clear that daily spraying with pyrethrum had the most beneficial effect with a 91\% reduction in the spleen rate, despite a $2.86 \%$ sporozoite rate. The economics of anti-adult spraying compared with larviciding showed that spraying cost about a third of the cost of larviciding and reduced the spleen rate by $50 \%$. In the area being treated with larvicides the spleen rate actually went up. ${ }^{[13]}$

Dr Fred Soper from the Rockefeller Foundation attended this League of Nations conference and afterwards visited the malaria research station at Eshowe. He rejected the concept of vector control by indoor insecticide spraying stating that for every female anopheline that came indoors, there would be hundreds outdoors and out of reach of the insecticide. $^{[5]}$ De Meillon's work ${ }^{[12]}$ showing that the indoor resting proportion of the mosquito populations were the ones infected with parasites, was ignored. Soper, however, just a few years later, made excellent use of the very same indoor spraying strategy to rid Brazil of An. gambiae. ${ }^{[20]}$ He subsequently met Professor James Gear from the SAIMR at a Rockefeller Institute meeting and asked him to convey his apologies to the South African 'malaria officers. ${ }^{\text {[5] }}$

Sir Gordon Covell, on the other hand, also a participant at the League of Nations conference, immediately recognised the enormous benefits of the work being done in SA. At the time he was with the British Army in India and on his return to that country implemented a similar control strategy with great success. ${ }^{[21]}$

The distribution of malaria is illustrated in a 1938 map produced by the Department of Public Health (Fig. 3) showing the endemic areas, with epidemic malaria occurring as far south in the Transvaal as Pretoria and in Natal to beyond Durban.

\subsection{Transvaal}

Prior to the Pan-African Health Conference in 1936, De Meillon had been carrying out extensive studies in the Tzaneen area of the northern Transvaal. Here he showed that the vector mosquitoes rested indoors for several days after taking a blood meal before leaving the house to lay eggs. ${ }^{[12]}$ This led directly to the strategy of indoor house spraying used globally when residual insecticides such as dichlorodiphenyltrichloroethane (DDT) became available after World War II. 
The early work of Annecke in the Transvaal, from the time that the malaria station was established in 1932 until the early 1940 s, consisted mainly of advocacy and training - teaching the communities how to protect themselves through treatment, improved housing construction, screening and insecticidal spraying. Over 600 depots were established in rural areas to provide free quinine to the communities. Annecke states: 'Those who took notice (or who possessed the means to do so) lived mostly malaria free. ${ }^{[22]}$ The vast majority, however, suffered enormously with hundreds of deaths recorded annually throughout the Transvaal Lowveld. Annecke carried out these activities initially with the help of three health inspectors, two lady health visitors, one technical assistant and four 'spotters'. Between 1937 and 1944 the staff complement was increased to 14 health inspectors, four lady health visitors and three technical assistants. 'Propaganda was intensified but did not yield greatly improved results ${ }^{5[2]}$ and major malaria epidemics were recorded in 1939 and 1943. During the 1939 epidemic, 9311 malaria deaths were reported in the Transvaal.

It was not until 1944 when the Farmers' Union made urgent appeals to the government for help that things started to change. The first meeting between the Farmers' Union representatives and the Secretary for Public Health took place on the Springbok Flats, an area devastated by the 1943 malaria epidemic to a point where huge crop losses were experienced because labour could not be found to reap the crops. Amid soaring global food prices, many farmers in this area were facing bankruptcy and land values had plummeted. ${ }^{[22]}$ With a substantial grant from Treasury, Annecke, together with the local farmers, embarked on a full-scale malaria control operation using pyrethrum knockdown insecticide for adult mosquitoes (DDT being very new and in short supply) and oil for larviciding. This programme functioned for three years but malaria had already virtually vanished one year after operations began. Annecke recorded that this operation was carried out with no guidance on appropriate staffing and materials. ${ }^{[2]}$

Treasury almost trebled the grant for the malaria programme in 1944/45 and Annecke rolled out vector control to as much of the Transvaal Lowveld as existing staffing allowed. DDT for house spraying was introduced in 1945. The results were dramatic.

\section{Post World War II, 1945 - 1950}

In the spring of 1944 towards the end of World War II, field trials in the Nile Valley and Naples, Italy, demonstrated the usefulness of DDT to control malaria as well as louse-borne typhus. Initially the formula for DDT was a closely guarded military secret but a member of the South African Medical Corps, Major Neil Murray, found it in Popular Mechanics. ${ }^{[3]}$

The South African Government was quick to realise the potential of DDT for public health purposes and the feasibility of producing it in the country was investigated. It involved close liaison between the Departments of Public Health, Defence and Agriculture, with assistance from the British and American Governments. ${ }^{[23]}$ This led to the construction of a manufacturing plant at Modderfontein outside Johannesburg, where large amounts of DDT were produced. ${ }^{[3]}$ Its first use in SA was to control an outbreak of typhus in the Middleburg district of the Transvaal, achieving such dramatic success that it was made freely available to people in the Transkei who were experiencing a similar outbreak. After discussion with Prof. James Gear and Dr Botha de Meillon, Dr Eksteen, Member of Parliament for Middleburg, proposed in Parliament that DDT should be used for malaria control by indoor house spraying. ${ }^{[3]}$

\subsection{Initial trials with DDT}

The first SA trials with DDT were conducted in the Transvaal and described by Annecke in the 1945 Department of Public Health annual report. ${ }^{[23]} \mathrm{He}$ received the first shipment of DDT in mid-1944 - a very small quantity that proved to be insoluble, even in kerosene, resulting in 'no conclusive work'. At the beginning of 1945, a new formulation was received resulting in less clogging of the spray pumps. Between October 1945 and June 1946, extensive field trials were conducted in various localities around Tzaneen. A comparison was made between DDT sprayed and unsprayed huts at Thabina, with a considerable reduction in vectors caught in the huts (Table 2). Cost comparisons were also made between DDT spraying and weekly pyrethrum spraying, indicating that weekly spraying was up to 20 times more expensive than DDT spraying. The results of the Thabina trials, as well as similar trials at Hlabisa in Zululand comparing DDT with weekly pyrethrum spraying (Table 3), were published in 1946. ${ }^{[24]}$ This report concluded: 'Experiments so far carried out indicate that the application of a 5 per cent DDT solution (in kerosene) offers a more economical and effective method of malaria (mosquito) control in ... rural areas than any other method previously tried by this Department. ${ }^{[24]}$

During these trials, comparisons were also made between DDT 5\% in kerosene and malaria oil, both used as larvicides. These trials also included experimental attempts to spray DDT on water by means of an aircraft. The results of these trials were inconclusive, as it did not demonstrate residual benefits of DDT.

The results of these studies paved the way for introducing and expanding vector control in 1946 through indoor residual spraying (IRS), offering far better results than previously achieved through weekly indoor space spraying. The coverage was extended to areas not formerly controlled including many rural areas. ${ }^{[25]}$ Annecke summarised the malaria control programme in the Transvaal as follows: ${ }^{[22]}$

- 'Larviciding (using oil, but busy replacing oil with DDT emulsion) applied fortnightly in summer to all breeding places and monthly in winter, to the proven winter breeding sites'.

- 'Larviciding is combined with the use of a residual insecticide. 5\% DDT in kerosene

Table 2. Adult mosquitoes collected from 26 huts in Thabina, Transvaal, from October 1945 to March $1946^{[24}$

\begin{tabular}{|c|c|c|}
\hline \multirow[b]{2}{*}{ Week } & \multicolumn{2}{|c|}{ Adult mosquitoes caught, $n$} \\
\hline & $\begin{array}{l}\text { DDT sprayed } \\
\text { section }\end{array}$ & $\begin{array}{l}\text { Control } \\
\text { section }\end{array}$ \\
\hline 1 & 0 & 218 \\
\hline 2 & 2 & 376 \\
\hline 3 & 0 & 415 \\
\hline 4 & 5 & 502 \\
\hline 5 & 4 & 707 \\
\hline 6 & 5 & 500 \\
\hline 7 & 16 & 830 \\
\hline 8 & 26 & 1116 \\
\hline 9 & 4 & 413 \\
\hline 10 & 5 & 468 \\
\hline 11 & 3 & 471 \\
\hline 12 & 27 & 720 \\
\hline 13 & 17 & 640 \\
\hline 14 & 13 & 189 \\
\hline 15 & 1 & 347 \\
\hline 16 & 34 & 1015 \\
\hline 17 & 101 & 852 \\
\hline 18 & 214 & 1064 \\
\hline Total, $N$ & 477 & 10843 \\
\hline
\end{tabular}


Table 3. Adult mosquitoes collected from 10 huts in each of the $\mathbf{4}$ sections in Hlabisa, Zululand, from February to May $1946^{[24]}$

\begin{tabular}{lllll}
\hline & \multicolumn{3}{l}{$\boldsymbol{n}$} \\
\cline { 2 - 5 } Week & DDT section & Pyrethrum section $\mathbf{1}$ & Pyrethrum section 2 & Control section \\
\hline 1 & - & 21 & 18 & 22 \\
2 & - & 23 & 21 & 56 \\
3 & 1 & 34 & 24 & 60 \\
4 & - & 56 & 44 & 90 \\
5 & - & 137 & 30 & 115 \\
6 & 2 & 186 & 41 & 148 \\
7 & - & 127 & 52 & 130 \\
8 & 2 & 145 & 14 & 136 \\
9 & 1 & 210 & 54 & 107 \\
10 & 1 & 105 & 30 & 69 \\
11 & - & 54 & 31 & 81 \\
12 & - & 37 & 9 & 127 \\
13 & 2 & 46 & 17 & 39 \\
14 & - & 66 & 18 & 47 \\
Total, $N$ & 9 & 1247 & 403 & 1227 \\
DDT = dichlorodiphenyltrichloroethane. & & &
\end{tabular}

was used in westernised houses, with $50 \%$ DDT wettable power in traditional houses. DDT was applied every 3 to 4 months. In the epidemic prone or low risk areas, DDT was used alone, applied once or twice a season'.

In the Transvaal, the operations were mostly implemented by the Union Department of Public Health, with a vertically structured malaria control unit, administratively divided into five zones. In Natal, malaria control was implemented through 'Statutory Malaria Committee' areas, with activities paid through refunds to the committees, by the Department of Public Health.

The other major contribution made by De Meillon in these early years was the detailed descriptions of the anopheline mosquitoes of sub-Saharan Africa. ${ }^{[26,2]}$ These works were invaluable for the malaria vector control programmes' surveillance activities, enabling accurate identification of the vector species.

\section{The eradication era, 1950 - 1970}

The impact achieved through of IRS of houses was widely lauded and documented. Various indicators were used to demonstrate the successes, among these a reduction in vectors collected in dwellings, decline in the use of quinine, parasite and spleen rates, and the economic benefits. In 1951, Annecke reported extensively in the Department of Public Health's annual report on the impact of IRS in the Transvaal. ${ }^{[28]}$ The use of 5 grain quinine tablets dropped from 2000000 in $1943 / 44$ to 94000 in 1950/51. The dramatic decline in parasite and spleen rates between 1931 and 1951 is shown in Table 4. This was based on blood smears taken from the local population at the peak of the malaria season outside Tzaneen, Transvaal.

In 1952, the Minister of Health for the Union of SA, gave a radio broadcast on the economic benefits modern malaria control had brought to the Transvaal: ‘.. 10000 square miles containing some of the country's richest farming land in the world for sub-tropical fruit; yet only fifteen years ago this area was shunned by Europeans, and those [locals] who survived to young adult life lay ill in the kraal just when they should have been reaping their crops. In the hyperendemic zones of Pongola - a few years ago almost a deserted region - the disappearance of malaria gives a fair chance that within five years the area will be producing about $20 \%$ of the sugar cane grown in the Union..$^{\text {[29] }}$

Several threats to the continued success of the malaria control programme were perceived, among these vector resistance to insecticides and parasite resistance to treatment. Cross-border malaria was also highlighted as a major threat for the ongoing programme success. In the Transvaal, transmission was affected by poor control in Bechuanaland (Botswana), Southern Rhodesia (Zimbabwe), Mozambique and Swaziland. In Natal, the impact that uncontrolled areas were having on controlled areas was reported on many occasions. In 1953, an outbreak in the Nongoma and Hlabisa districts in Natal was attributed to the lack of control in the adjacent rural areas, as Malaria Committees were not in place in these areas. This prompted the expansion of control measures to Ubombo and Ingwavuma in 1953. By 1956, malaria infections had been reduced to negligible figures. ${ }^{[30]}$

Towards the end of 1959, a WHO assessment team visited the malarious provinces in SA and a full appraisal of the malaria situation in the country was made, with resulting recommendations towards the eradication of malaria in the country. ${ }^{[3]}$

The assessment team recommended that Natal be divided into three zones, namely the transmission zone (northern parts of Natal), the consolidation zone and the vigilance zone. For the transmission zone, the full-scale attack phase of an eradication programme was recommended, with total residual insecticide house spraying

Table 4. Reduction in parasite and spleen rates among different age groups in $1931^{[22]}$ and $1951^{[28]}$ in the Transvaal

\begin{tabular}{|c|c|c|c|c|}
\hline \multirow[b]{2}{*}{ Age (years) } & \multicolumn{2}{|r|}{$1931, \%$} & \multicolumn{2}{|c|}{$1951, \%$} \\
\hline & With parasites & With enlarged spleen & With parasites & With enlarged spleen \\
\hline $0-1$ & 62 & 62 & 6 & 0 \\
\hline $2-5$ & $110^{*}$ & 93 & 8 & 2 \\
\hline $6-10$ & 98 & 90 & 10 & 3 \\
\hline $11-15$ & 70 & 77 & 7 & 3 \\
\hline $16-20$ & 57 & 56 & 3 & 1 \\
\hline$>20$ & 33 & 44 & 1 & 1 \\
\hline
\end{tabular}




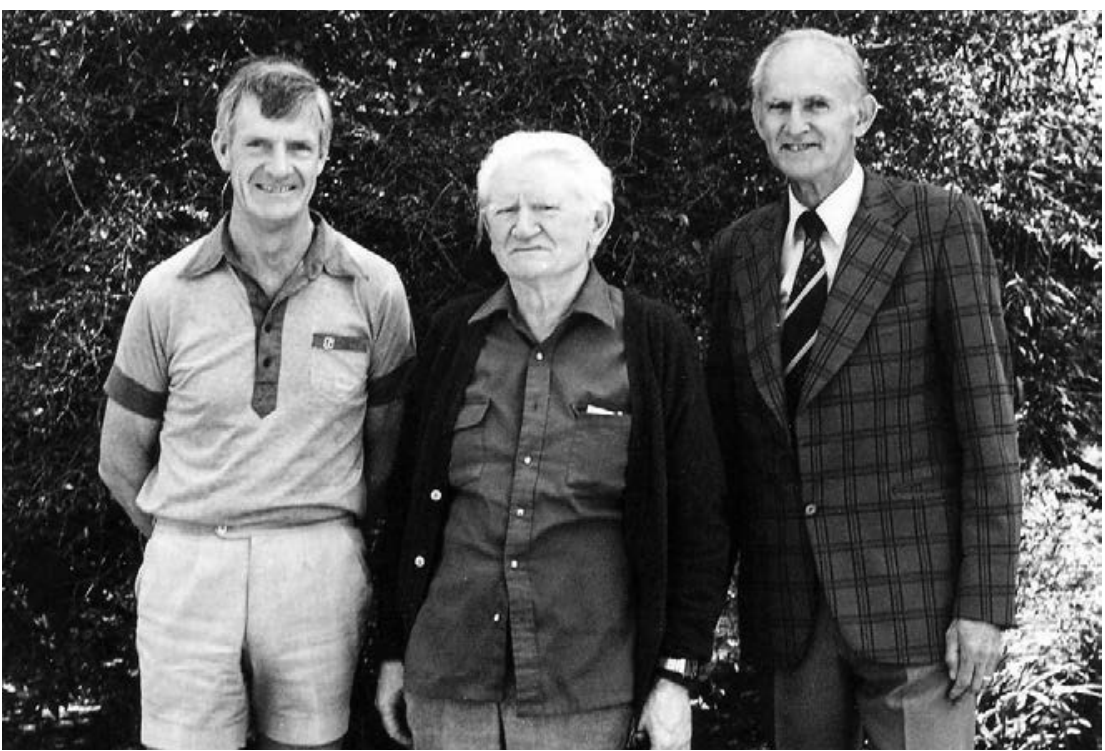

Fig. 4. From left, Hugh Paterson, Botha de Meillon and Gideon van Eeden, circa 1980.

coverage throughout the area. The high levels of malaria in southern Mozambique were highlighted as a threat. As the border with Mozambique was only a geographical boundary line, free movement of people took place, without any administrative formalities. The establishment of checkpoints along the Mozambique border, to intercept migrants and administer treatment was considered. Mozambique was also preparing to introduce a malaria eradication programme, which would provide protection to Natal.

For the consolidation zone, IRS was to be discontinued and retained only as an emergency measure, with the implementation of a surveillance system. As there was no evidence of malaria transmission in the vigilance zone, from 1954 this area was considered to be clear of malaria with ongoing surveillance recommended.

For malaria control purposes, the Transvaal was divided into four zones as confirmed by the WHO team, with malaria transmission only occurring in zone 1 (the north-eastern Lowveld areas) and zone 4 (Bushbuckridge, Nelspruit, Komatipoort and Barberton). In the other two zones, only sporadic cases of malaria were reported, with spraying discontinued and control maintained through selective larviciding. However, with the influx of parasite carriers from Zimbabwe and Mozambique still occurring, the need for implementing malaria eradication projects in these neighbouring countries as part of the southeast Africa malaria eradication programme was essential. It was recommended that IRS be continued in the transmission zones and that the cessation of IRS should depend upon progress in the adjacent countries.
All research on malaria vectors had ceased with the widespread implementation of IRS in the 1950s. De Meillon had been told by the Director of the SAIMR to stop working on mosquitoes because the malaria problem had been solved (Botha de Meillon, personal communication). Elsewhere in Africa, however, interesting observations were being made on the vector mosquitoes that would lead to a much better understanding of apparent 'failures' of vector control in southern Africa. Among these pioneers was a South African, Hugh Paterson (Fig. 4), working then for the SAIMR arbovirus unit, who in his spare time studied malaria mosquitoes. He was one of the key figures in unravelling the An. gambiae complex, demonstrating that at least three fresh-water breeding species existed and that one of them fed only on cattle and did not transmit malaria. ${ }^{[32]}$ This formed the basis for all subsequent research on these important vectors and explained anomalies like that found in Swaziland where indoor spraying had apparently caused the mosquitoes to change their behaviour from biting humans indoors to biting cattle outdoors.

From 1960 to 1966, the endemic malaria areas in the Transvaal and Natal experienced a severe drought. As the conditions did not favour the breeding of vector mosquitoes, malaria was at very low levels during this period. After the prolonged drought, heavy rains fell in 1967, resulting in conditions favouring the breeding of An. gambiae in temporary pools and An. funestus in small perennial streams. A sharp, but restricted epidemic occurred in the Komatipoort area of the eastern Transvaal, the first since the mass control campaign was undertaken in $1945 .^{[3,33]}$ In 1969 , malaria transmission increased in the north-eastern Transvaal where house spraying had been discontinued due to the low number of cases. House spraying with DDT was reintroduced but the lack of qualified and experienced entomological personnel was recognised as a major problem. Mr Gideon van Eeden (Fig. 4), having just returned from Swaziland where he obtained extensive entomological training under Dr O Mastbaum, was the only employee available to undertake entomological monitoring.

\section{Malaria under control, 1970 - 1995}

Widespread rains over a prolonged period in 1971 - 1972 resulted in a severe and extensive epidemic during 1972. ${ }^{\circ}$ Due to insufficient personnel and delays caused by the rain, house spraying was not completed and patients with malaria could not be adequately traced. In the Komatipoort area, the sugar cane industry was being constructed with land clearing providing suitable larval breeding habitats. Migrant workers housed themselves in plastic bag shelters and were exposed to vectors. Over 3700 indigenous malaria cases were confirmed throughout the Transvaal and at the peak of the epidemic, 600 infections were confirmed in a single week from Komatipoort.

The epidemic sparked a debate in the National Assembly. While the Minister of Health explained the epidemic as being 'under control', he did commit to visiting the malaria control areas and proposed the strengthening of the programmes. There was also an undertaking to take the matter up with the neighbouring countries Mozambique and Rhodesia (Zimbabwe), as

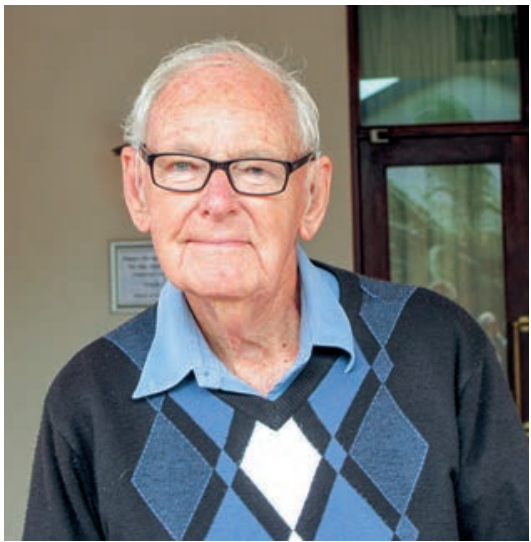

Fig. 5. Frank Hansford (1926 - present).

'Although this epidemic was considered to be 'severe', it wa only in relation to the transmission that had been recorded in this, as can be 
these two countries appeared to contribute to the problems in SA.

This resulted in the number of malaria teams being almost doubled and allowed for the construction of an insectary at Tzaneen in 1972. It also resulted in a visit from the WHO, whose representatives spent a week in the northern Transvaal assessing the situation.

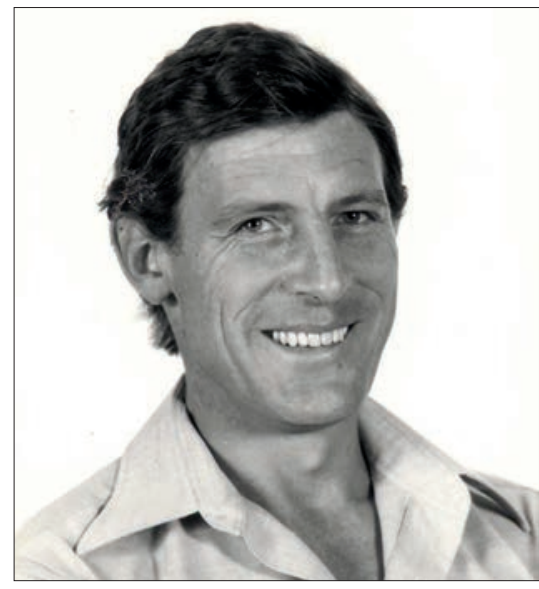

Fig. 6. Chris Green (1942 - 1997).

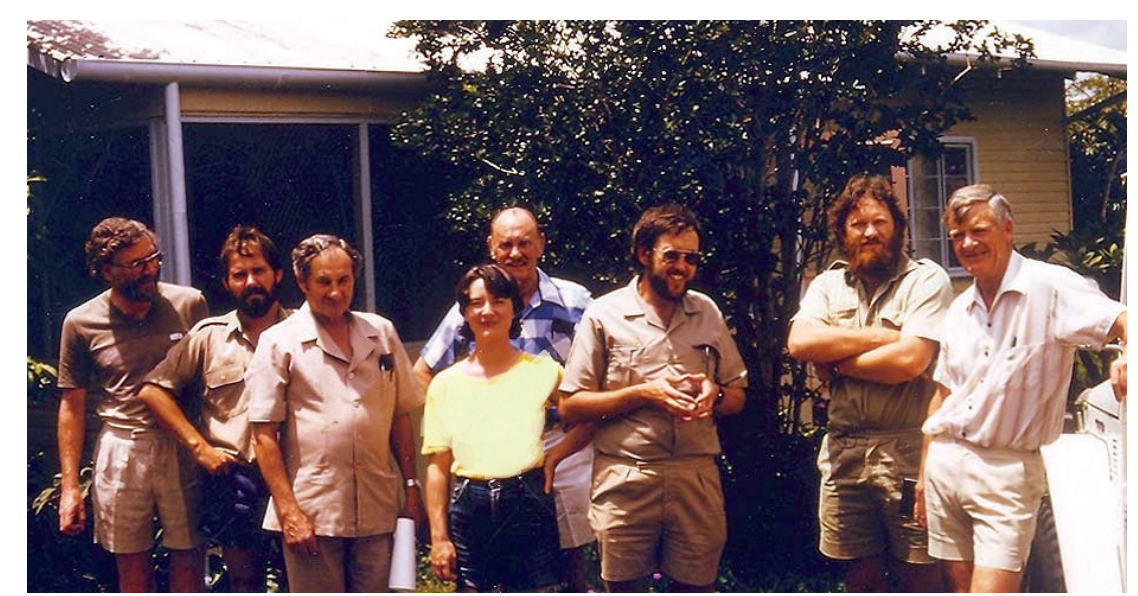

Fig. 7. From left, Richard Hunt (SAIMR), Dave le Sueur (SA Medical Research Council (MRC)), Ed Hartwig (Department of Health (DoH)), Debbie Walpole (University of the Witwatersrand), Jan Jansen (DoH), Dirk Theron (DoH), Brian Sharp (MRC), Hugh Paterson (University of the Witwatersrand), circa 1984.

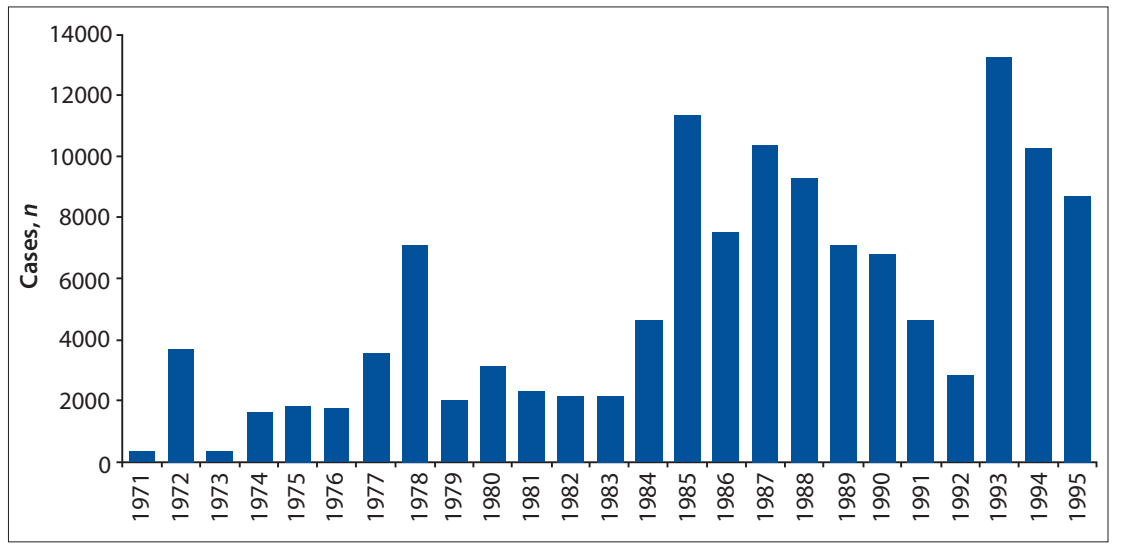

Fig. 8. Malaria case data 1971 - 1995 (data from the National Department of Health and unpublished documents).

The outcome was that three senior WHO personnel were posted to Tzaneen from 1973 to 1976 - a medical malariologist (Dr J Lilyveld), an entomologist (Dr A Smith) and a malaria technical officer seconded from USAID (Mr J Thompson). In 1973, the National Department of Health (DoH) revived the 'malaria office' at Tzaneen with a medical officer (Dr Frank Hansford; Fig. 5), two entomologists (Dr Neethling du Toit and Mr Gideon van Eeden) and field and laboratory staff to assist the WHO team. The Tzaneen 'malaria office' became known 'Siegfried Annecke Institute', but Tropical Diseases in 1979, and was responsible for malaria control in all the malarious regions of SA. At the same time, Botha de Meillon, then in his 70s, was employed as a consultant to assist with entomological investigations. Capacity for identifying the members of the An. gambiae complex was increased through the establishment of an electrophoresis laboratory in Tzaneen, set up with the help of the Rhodesian entomologists who had developed the method. ${ }^{[34]}$ Chris Green (Fig. 6) and Richard Hunt (Fig. 7) subsequently joined the Department of Medical Entomology, SAIMR, in 1978, thereby strengthening the research capacity on malaria vector mosquitoes. Further capacity for entomological research was created by the SA Medical Research Council (MRC) at their Research Institute for Diseases in a Tropical Environment in Durban. Brian Sharp was employed in 1980 and was later joined by David le Sueur (Fig. 7). Together, they set up the Lubombo Spatial Development Initiative (LSDI) Malaria Control Programme in 1999, described below.

In 1978, again following heavy rains, a severe epidemic occurred in an unsprayed area, Bolubedu, east of Tzaneen, with 1468 cases reported in April of that year. Again, additional resources were made available for malaria control, this time to the Lebowa government (one of the newly established 'homelands'). ${ }^{[35]}$ Subsequent to the outbreak, all dwellings were sprayed and in spite of extensive surveillance, no infections were found the next year.

Apart from these two epidemics, malaria cases seldom exceeded the 4000 case level until the mid-1980s when: $(i)$ chloroquine drug resistance was detected in the parasites in Natal, ${ }^{[36-38]}$ and (ii) migration from Mozambique increased due to political disturbances in that country (Fig. 8). This resulted in annual cases being consistently over 6000 for six consecutive years, reaching over 10000 in two of them. Once first-line treatment in Natal was changed to sulphadoxine-pyrimethamine malaria transmission reverted briefly to previous levels (Fig. 8), but resurged again in 1993 when chloroquine resistance was detected in the Transvaal and climatic conditions favoured mosquito breeding.

In the 1980s, new insecticides became available for malaria vector control. Synthetic pyrethroids were developed for both IRS of houses and for treating bednets, while carbamates were adapted for house spraying. Pyrethroids in particular were tested extensively for their residual efficacy to see if they could replace DDT, which had become unacceptable to the local communities because of increased resistance in the bedbug populations ${ }^{[39]}$ and the marks left on the walls after spraying. ${ }^{[40,41]}$ DDT had also received negative press regarding

${ }^{\mathrm{d}}$ Rhodesia at that time had an excellent malaria control programme under the leadership of Drs V de V Clarke and
Clive Shiff at the Blair Research Laboratory in Harare and therefore that country's contribution to SA's malaria case burden would have been negligible. The Rhodesians were very happy to share their expertise with SA and a delegation from Tzaneen visited Harare around 1976 to learn about the new entomological techniques for identification of species of the
An. gambiae complex. 
its persistence in the environment and in the food chain. By 1994, the SA National Malaria Control Programme had decided to change policies and switch from DDT to pyrethroids for IRS, and this change came into effect in $1995 .^{[42]}$

Also, in 1994 there was a change of government in SA, with a redrawing of the provincial boundaries resulting in the central malaria control programme run from Tzaneen being devolved to the four malarious provinces: KwaZulu-Natal (KZN), Mpumalanga (former Eastern Transvaal), Limpopo (former Northern Transvaal) and North West (former South-Western Transvaal and Northern Cape) provinces. Kobus la Grange, one of the managers for the Mpumalanga programme, subsequently went on to manage Phase 2 of the LSDI programme in Mozambique before his death in 2009.

The DoH established a Malaria Advisory Group in 1994 comprising of the SA Malaria Control Programme manager under the leadership of Dr Neil Cameron, Director for Communicable Diseases, key control programme personnel such as the regional managers and entomologists, research institutions and the military. Prof. Jan van den Ende, the Director of the SAIMR, chaired the committee. This group provided guidance and advice on malaria control policy and strategy and was to play a key role in the epidemic of 1999/2000.

\section{1996 - present}

Along with the policy change in 1995 to move away from the use of DDT for IRS, border controls were relaxed, particularly on the northern KZN/Mozambique border, resulting in many rural Mozambicans travelling to SA in search of treatment for illness, including malaria. Rainfall was also particularly good during this period. This combination of events saw the number of malaria cases leap from 8750 in 1995 to 27035 in 1996 and remain there for the next two years (Fig. 9). In 1999, the number of cases doubled to 51444 and in 2000 hit a peak of 64 622, the highest number of cases recorded since the introduction of DDT for IRS.

Entomological investigations carried out in northern KZN Province by Keith Hargreaves, in collaboration with entomologists from the SAIMR, showed that An. funestus had returned to SA and was resistant to the pyrethroids being used for IRS. ${ }^{[43]}$ Out of 52 mosquitoes collected along the Mozambique border, 5.4\% were infected with $P$. falciparum. Furthermore, in 2000 it was shown that the first-line drug for treatment of malaria in SA, SP, was failing. On the recommendation of the Malaria Advisory Group, DDT was reintroduced for the spraying of traditional structures, while pyrethroids were maintained for westernised housing, effectively implementing a mosaic strategy for resistance management. The following year, artemisinin-containing combination treatment (ACT) was introduced for treatment of the disease.

SA's decision to reintroduce DDT to control the epidemic was made in the face of considerable pressure against the insecticide, and indeed against all insecticides. Similarly, the country's decision to adopt the use of ACT was made at a time when the WHO had not changed official treatment policy, and did not issue new treatment guidelines for another 6 years. Not only had the WHO encouraged countries to reduce their reliance on insecticides, no major donor agency would sanction the use of DDT in any IRS programme. In 2000, at the height of SA's malaria epidemic, the Stockholm Convention on Persistent Organic Pollutants, held its fifth

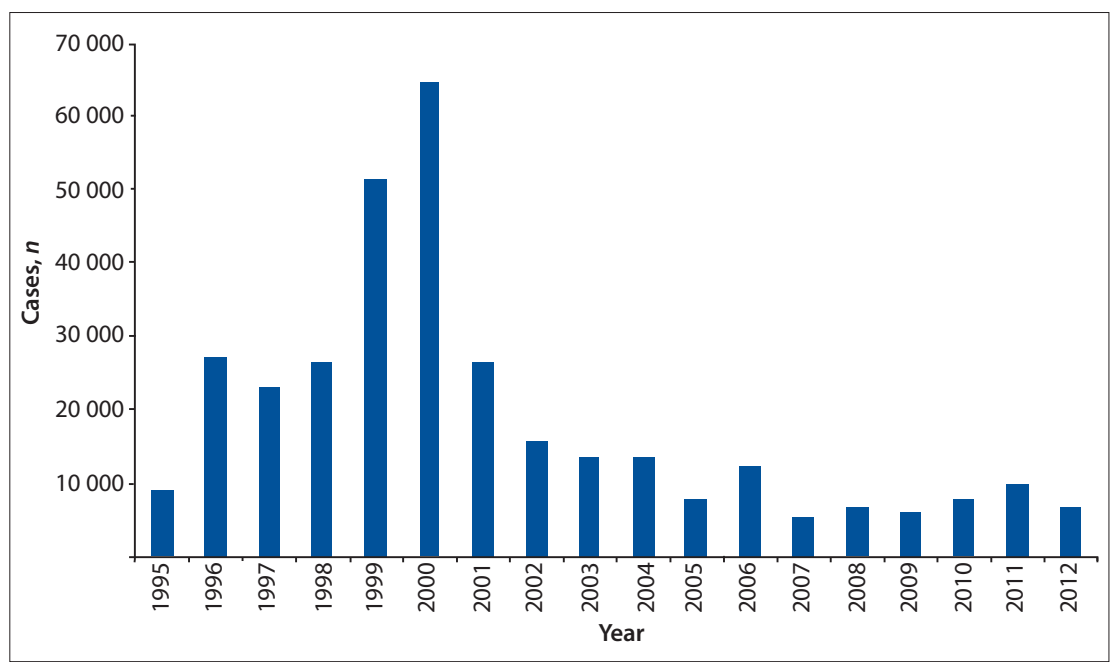

Fig. 9. Malaria cases in South Africa, 1995 - 2012 (data from the National Department of Health). and final negotiating committee meeting in Johannesburg. National government, with the assistance of international scientists and an independent advocacy group, succeeded in securing an exemption for not only the South African National Malaria Control Programme but all national malaria control programmes wishing to use DDT for malaria vector control purposes.

\subsection{The Lubombo Spatial Development Initiative}

The LSDI Malaria Control Programme was officially inaugurated in October 1999 by the signing of a protocol by the Ministers of Health of the three countries: SA, Swaziland and Mozambique. The signing of this protocol established the Regional Malaria Control Commission, comprised of malaria scientists and control and public health specialists from the three countries. The overall objective of the LSDI was to reduce the incidence of malaria in Maputo Province in southern Mozambique and thus contribute to its reduction in the adjoining border areas of SA and Swaziland. Under the leadership of Brian Sharp from the MRC, this programme was rolled out with the financial support of the Global Fund to Fight AIDS, TB and Malaria. Initially, vector control using IRS of houses with pyrethroids was planned. However, subsequent to the demonstration by SAIMR and KZN entomologists in northern KZN Province that the An. funestus vector population was highly resistant to pyrethroids, ${ }^{[43]}$ work was carried out by Richard Hunt and Graham Kloke at the Mozal Aluminium Smelter in Maputo, Mozambique, confirming both pyrethroid and carbamate resistance in An. funestus populations in southern Mozambique. ${ }^{[4]}$ Nevertheless, bendiocarb was used for IRS in southern Mozambique starting in 2000. Despite the fact that the An. funestus population showed low levels of resistance to bendiocarb, during the period 1999 - 2005 the parasite prevalence rate in the human population decreased from $65 \%$ to $4 \% \cdot{ }^{[45]}$

\subsection{Capacity building and other regional collaboration}

The African Regional Office of the WHO created the African Network for Vector Resistance (ANVR) in 1999. This initiative was used to increase awareness of insecticide resistance in the vector mosquitoes in all the malarious countries in the WHO-Afro Region. Training courses in vector resistance and resistance management were held at the SAIMR in Johannesburg annually from 2000 to 2003 for Anglophone countries, while 
similar courses were held in Cameroon for French-speaking countries. Approximately 80 people from 40 African countries were trained in basic vector control entomology during this initiative.

South Africans have been key participants in many expert regional and international committees over the decades. These began with De Meillon and Park Ross' participation in the League of Nations meetings prior to World War II and De Meillon's appointment as a WHO consultant in Brazzaville in the 1960s. Currently, SA is represented on the Roll Back Malaria Vector Control Working Group (M Coetzee and R Maharaj), the Stockholm Convention DDT Expert Committee and the WHO Global Malaria Programme's Technical Expert Group (M Coetzee), and the WHO Global Malaria Programme's Treatment Guidelines group (K Barnes). The SA National Malaria Control Programme personnel participate on SADC and WHO/AFRO committees that consider malaria as a regional problem. Not least, the immensely popular SA singer, Yvonne Chaka Chaka, holds the appointment of UN Goodwill Ambassador for Malaria.

\section{Conclusion}

Over the past 100 years, SA has made enormous strides in controlling the transmission of malaria, particularly since World War II and the advent of DDT for house spraying. Probably the most important lesson learned over the years has been the need for constant vigilance and surveillance of vectors and parasites. Where these have faltered, we have seen increases in transmission, sometimes dramatically so, as in the 1999 - 2000 epidemic.
References

Harrison G. Mosquitoes, Malaria and Man: A History of the Hostilities since 1880. London: John Murray, 1978.

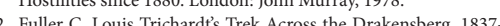
1838. Cape Tow: The Van Riebeck Sociely 1932 .

1838. Cape Tow: The Van Rebeck Soc 1932. Gear JHS. Malaria in South Africa: Its history and present problems. South Afr J Epidemiol Inf 1989;4:63-66.

4. Laidler PW, Gelfand M. South Africa: Its Medical History. Cape Town: Struik, 1971.

5. Malan M. In Quest of Health. The South African Institute for Medical Research 1912 - 1973. Johannesburg: Lowry Publishers, 1988

6. Hill E, Haydon LG. The epidemic of malaria fever in Natal. J Hyg 1905;5:467-484. [http://dx.doi.org/10.1017/ S0022172400006781

7. Pratt-Johnson J. The distribution of malaria in South Africa and a mosquito survey of military hospital areas. J Hyg 1921;19:344349. [http://dx.doi.org/10.1017/S0022172400007932]

8. Murison P. Epidemic of Malaria in Durban, 1905-1907. In: Ross R, ed. The Prevention of Malaria. Section 56. London: John Murray, 1910:549-553.

9. Bostock L. Malaria in South Africa. In: Ross R, ed. The Prevention of Malaria. Section 55. London: John Murray, 1910:543-548.

0. Ingram A, De Meillon B. A mosquito survey of certain parts of South Africa, with special reference to the carriers of malaria and their control. Parts I and II. Publ S Afr Inst Med Res 1929;4:1-179.

11. Ingram A, De Meillon B. Efficacy of certain reagents as destructors of flies when used in the form of a spray. J Med Assoc S Afr 1927; 1:366-369.

12. De Meillon B. Entomological studies. Observations on Anopheles funestus and Anopheles gambiae in the Transvaal. Publ S Afr Inst Med Res 1934;6:195-248.

13. De Meillon B. The control of malaria in South Africa by De Meillon $B$. The control of malaria in South Africa by
measures directed against adult mosquitoes in habitations. measures directed against adult mosquit

14. Anonymous. Prevention of malaria. Foreign Letters. J Am Med Assoc 1930;742.

Assoc 1930;742.
15. Swellengrebel NH, Annecke S, De Meillon B. Malaria investigations in some parts of the Transvaal and Zululand. Publ S Afr Inst Med Res 1931;4:245-274

6. Park Ross GA. Insecticide as a major measure in control of malaria, being an account of the methods and organisations put in force in Natal and Zululand during the past six years. Quart Bull Hlth Org L o N 1936;5:114-133.

17. Union of South Africa. Annual Report of the Department of Public Health. Pretoria: Government Printer, 1932.

8. Union of South Africa. Annual Report of the Department of Public Health. Pretoria: Government Printer, 1933.

19. Le Sueur D, Sharp BL, Appleton CC. Historical perspective of the malaria problem in Natal with emphasis on the period 1928the malaria problem in Natal with

20. Soper F, Wilson DB. Anopheles gambiae in Brazil, 1930 to 1940. New York: Rockefeller Foundation, 1943

21. Covell G, Mulligan HW, Afridi MK. An attempt to control malaria by the destruction of adult mosquitoes with insecticidal sprays. J Malar Inst India 1938;1:105-113.

22. Annecke S. Report on malaria control in Transvaal. Unpublished document WHO/MAL.48. Geneva: World Health Organization, 1950.

23. Union of South Africa. Annual Report of the Department of Public Health. Pretoria: Government Printer, 1945,

4. Union of South Africa. Annual Report of the Department of Public Health Pretoria: Government Printer 1946.
25. Union of South Africa. Annual Report of the Department of Public Health. Pretoria: Government Printer, 1947.

26. De Meillon B. Illustrated keys to the full-grown larvae and adults of South African anopheline mosquitoes. Publ S Afr Inst Med Res 1931;4:275-375.

27. De Meillon B. The Anophelini of the Ethiopian geographical region. Publ S Afr Inst Med Res 1947;49.

28. Union of South Africa. Annual Report of the Department of Public Health. Pretoria: Government Printer, 1951.

29. Union of South Africa. Annual Report of the Department of Public Health. Pretoria: Government Printer, 1952.

30. Nethercott AS. Forty years of malaria control in Natal and Zululand. S Afr Med J 1974;48:1168-1170.

31. World Health Organization. Report of the Malaria Assessment Team on the present situation in the Northern Transvaal and Natal. Unpublished WHO documents. Geneva: World Health Organization, 1960.

32. Paterson HE. Direct evidence for the specific distinctness of forms A, B and C of the Anopheles gambiae complex. Riv Malariol 1964;43:191-196.

33. Hansford CF. Recent trends in the control and treatment of malaria. S Afr Med J 1972;46:635-637.

34. Mahon RJ, Green CA, Hunt RH. Diagnostic allozymes for routine identification of adults of the Anopheles gambiae complex (Diptera: Culicidae). Bull Entomol Res 1976;66:25-31. [http://dx.doi.org/10.1017/S0007485300006465]

35. Mphahlele M. Lebowa dilemma - the 1978 Malaria Epidemic. S Afr Med J 1980;54:1023.

36. Freese JA, Sharp BL, Ngxongo SM, Markus MB. In vitro confirmation of chloroquine-resistant Plasmodium falciparum malaria in KwaZulu. S Afr Med J 1988;74:576-578.

37. Hansford CF. Chloroquine resistance in Plasmodium falciparum in KwaZulu 1983-1988. S Afr Med J 1989;76:546547.

38. Herbst JM, Taylor LA, Joubert SM. In vitro chloroquineresistant Plasmodium falciparum malaria in the Natal/Kwazulu area. S Afr Med J 1985;68:749-750.

39. Newberry K, Jansen EJ, Quann AG. Bedbug infestation and intradomiciliary spraying of residual insecticide in KwaZulu, South Africa. S Afr I Sci 1984:80:377.

40. Govere JM, Durrheim DN, Kunene S. Malaria trends in South Africa and Swaziland and the introduction of synthetic pyrethroids to replace DDT for malaria vector control. S Afr J Sci 2002;98:19-21

41. Maharaj R, Mthembu DJ, Sharp BL. Impact of DDT reintroduction on the malaria transmission in KwaZulu-Natal. S Afr Med J 2005;95:871-874

42. Coetzee M. Malaria and dengue vector biology and control in southern and eastern Africa. Chapter 9. In:_Knols BGJ, Louis C, eds. Bridging Laboratory and Field Research for Genetic Control of Disease Vectors. Wareningen. UR Frontis Series Con 2005 101-109. 11, 2005;101-109. http://library.wur.nl/ojs/index.php/frontis/
article/view/1189 (accessed 9 August 2013).

Hargreaves K, Koekemoer LL, Brooke BD, Hunt RH, Mthembu J. Coetzee M. Anopheles funestus resistant to pyrethroid insecticides in South Africa. Med Vet Entomol 2000;14.181189. [http://dx.doi.org/10.1046/j.1365-2915.2000.00234.x]

44. Brooke BD, Kloke G, Hunt RH, et al. Bioassay and biochemical analyses of insecticide resistance in southern African Anopheles funestus (Diptera: Culicidae). Bull Entomol Res 2001;91:265-272. [http://dx.doi.org/10.1079/BER2001108]

45. Sharp BL, Kleinschmidt I, Streat E, et al. Seven years of regional malaria control collaboration - Mozambique, South Africa, and Swaziland. Am J Trop Med Hyg 2007;76:42-47. 